\title{
FATORES QUE INFLUENCIAM NA ESCOLHA DO IFRN: UM ESTUDO DE CASO NO CAMPUS CEARÁ- MIRIM
}

\author{
S. B. RODRIGUES e M. F. F. S. TACCONI \\ Instituto Federal de Educação, Ciência e Tecnologia do Rio Grande de Norte. \\ silmararodrigues29@gmail.com
}

Artigo submetido em dezembro/2015 e aceito em dezembro/2015

DOI: 10.15628/empiricabr.2015.3805

\section{RESUMO}

A Gestão Pública tem como principal dever proporcionar os meios de garantir que seus serviços sejam prestados com qualidade, atingindo seus resultados. Ao reconhecer esta visão é importante criar estratégias para identificar necessidades de novos projetos e definir direcionamentos dos serviços públicos. Os estudos em marketing, e comportamento do consumidor auxiliam na identificação do público-alvo e conhece as causas que o fazem a escolha por um serviço prestado. Como um dos principais pilares dos serviços públicos é a educação, o Instituto Federal de Educação, Ciência e Tecnologia do Rio Grande no Norte - IFRN tem atuado como agente de transformação ao expandir suas unidades pelo estado, tendo o município de Ceará-Mirim um dos beneficiados. O objetivo desta pesquisa é analisar os fatores que influenciam ao ingresso dos alunos do IFRN - CearáMirim, sendo estes pessoais, psicológicos e sociais. A metodologia foi do tipo descritiva e quantitativa, utilizada a Análise Fatorial Exploratória como técnica estatística. A coleta de dados foi obtida por meio de um questionário aplicado aos alunos do ensino técnico integrado ingressos em 2014 e 2015. Como resultados, os fatores que tiveram evidência para o ingresso dos alunos foram infraestrutura; marca; percepção sobre o prestígio da instituição; ascensão pessoal; a relação com a esportividade e a influência familiar. Conclui-se que os fatores psicológicos e pessoais foram os mais evidentes na escolha dos alunos, e os fatores sociais não foram relevantes para a escolha da instituição.

PALAVRAS-CHAVE: Gestão de Projetos de TI, Maturidade de Projetos, Alinhamento Estratégico de Negócio e TI

\section{FACTORS THAT INFLUENCE IN IFRN ENTERING: A CASE STUDY ON CAMPUS CEARÁ-MIRIM}

\begin{abstract}
Public Management has the primary duty to provide the means to ensure that its services are provided with quality and achieve results. Recognizing this view it is important to develop strategies to identify needs for new projects and set directions for public services. Studies in marketing and consumer behavior assist in target audience identification due to the comprehension of the causes that make consumers choose for a service. As one of the main pillars of public services is education, the Federal Institute of Education, Science and Technology of Rio Grande do Norte - IFRN has acted as an agent of change by expanding its units by the Rio Grande do Norte State, what includes the municipality of Ceará Mirim as one of its beneficiaries. The goal of this research is to analyze the factors that influence
\end{abstract}

student's enrollment at IFRN - Ceará Mirim, considering personal, psychological and social aspects. The methodology was descriptive and quantitative, using Exploratory Factor Analysis as a statistical technique. The data was obtained through a questionnaire administered to students of integrated technical education enrolled in 2014 and 2015. As a result, the factors that had evidence for admission of students were infrastructure; brand; perception about the prestige of the institution; personal ascension; relationship with sport and family influence. We concluded that psychological and personal factors were most evident in the choice of students, and social factors were not relevant to the choice of the institution.

KEYWORDS: IT Project Management, Project Maturity, Strategic Alignment of Business and IT, Balanced Scorecard. 


\section{INTRODUÇÃO}

A Gestão Pública tem como dever proporcionar os meios de garantir que seus serviços sejam prestados com qualidade, atingindo seus resultados. Sendo assim, é importante estar em conhecimento com a sociedade e o que a mesma precisa para que suas necessidades básicas como educação, saúde, segurança, moradia e lazer sejam supridas de forma condizente com o esperado.

Ao reconhecer a necessidade de conhecer a sociedade para o melhor direcionar os serviços à população, percebe-se a importância de traçar estratégias para a criação de projetos e definir públicos para o serviço. Os estudos em marketing auxiliam nessa identificação e conduz a execução dos serviços prestados, além de sugerir novas ideias para aperfeiçoar o que já está sendo desenvolvido.

Além da identificação e aperfeiçoamento, o marketing tem a função fundamental de estreitar relações entre a administração pública e o cidadão. As práticas de marketing favorecem na credibilidade do serviço público e na maior procura da população, já que a qualidade é um quesito de ênfase até para concorrentes vindos da esfera privada.

Nessa perspectiva, o presente estudo tem como objetivo pesquisar o perfil dos alunos dos cursos técnicos integrados do Instituto Federal de Educação, Ciência e Tecnologia do Rio Grande do Norte - Campus Ceará-Mirim-RN, tendo como objetivo identificar as variáveis sociais, pessoais e psicológicas que levaram os alunos na escolha da instituição, e avaliar o impacto dessas de variáveis, correlacionadas em fatores.

O trabalho apresenta como fundamentação teórica o marketing no serviço público e o comportamento do consumidor. Em seguida, foram aplicados os questionários para os alunos na obtenção de informações sobre o que influenciou na escolha do ingresso na instituição. Na sequência foram analisados os resultados e realizadas as considerações finais.

A presente pesquisa espera obter as aspirações e expectativas que os alunos têm em relação ao Instituto Federal. Essas informações adquiridas podem contribuir para que a instituição possa desenvolver novas estratégias alinhadas aos desejos e necessidades dos alunos e comunidade.

\section{REVISÃO BIBLIOGRÁFICA}

\subsection{O marketing e o serviço público}

Para entender melhor o conceito de marketing, não há uma tradução clara sobre o que significa na língua portuguesa, geralmente marketing traz uma tradução livre de "mercadologia". Os componentes que definem esse termo são as atividades relacionadas à troca; o intuito de satisfazer as necessidades e desejos de seus clientes/usuários; a finalidade de alcançar um objetivo da organização seja ela privada, pública ou terceiro setor; ressaltar a aceitação de um meio ambiente para que esta atuação seja feita; e o impacto que esta atuação possa implicar no bem estar das pessoas (LAS CASAS, 2005). 
O conceito de marketing de modo preciso faz com que seja visto de muitas formas, devido sua complexidade de estudo. Kotler (2000) aponta duas versões para sua definição: marketing como uma visão social focada para as necessidades das pessoas, e outra gerencial, direcionada nas práticas administrativas. O marketing segundo o autor "é um processo social por meio do qual pessoas e grupos de pessoas obtêm aquilo de que necessitam e o que desejam com a criação, oferta e livre negociação de produtos e serviços de valor com os outros." (KOTLER, 2000. p.30).

Kotler (2000), apresenta os estudos em marketing que implicam nos seguintes segmentos:

- Mercados-alvo e segmentação: é a identificação dos grupos de compradores e suas preferências.

- Profissionais de marketing e clientes potenciais: são os profissionais de marketing estão sempre buscando dos clientes potenciais para identificar o que estes desejam para que se faça a venda.

- Necessidades, desejos e demandas: são necessidades implicam nas exigências mais básicas dos clientes, essas necessidades se tornam desejos quando se tem um objeto específico para satisfazê-lo. Já as demandas são os desejos apoiados pela possibilidade de pagamento.

- Produto ou ofertas: produto é a oferta ao cliente para satisfazer suas necessidades ou desejos. Uma marca refere-se a um produto com uma fonte de credibilidade.

- Valor e satisfação: razão entre o que o cliente recebe e o que ele oferece.

- Troca e translações: troca é a obtenção de um produto desejado de alguém tendo oferecido algo. A transição envolve pelo menos duas coisas de valor, acordo com as condições estabelecidas, momento e local de acordo.

- Relacionamento e redes: relacionamento a fim de obter contato com clientes, funcionários, distribuições para fins de preferência e longevidade em seus negócios. E as redes são os relacionamentos mútuos entre a empresa e seus aliados.

- Canais de marketing: há mais três subdivisões, canais de comunicação, para transmitir e receber mensagens de seus clientes; canais de distribuição, que utiliza meios para demonstrar ou entregar produtos ou serviços tangíveis ao comprador; e os canais comerciais que se referem aos distribuidores, atacadistas e vendedores.

- Cadeia de suprimento: diferente dos canais de marketing, a cadeia de suprimentos são canais mais longos, que vão desde a matéria-prima até o consumidor final, ou seja, um sistema de entrega de valor.

- Concorrência: são as ofertas e substitutos rivais reais e potenciais que o cliente pode adquirir.

- Ambiente de Marketing: há duas subdivisões, ambiente de tarefas que envolvem os participantes imediatos na produção, distribuição e promoção do produto. E ambiente geral são os ambientes que influenciam no ambiente de tarefas.

- Mix de Marketing: é o conjunto de ferramentas do marketing que são usadas pela organização para atingir seus objetivos com o mercado-alvo. 
O Marketing possui quatro parâmetros em que formam o composto Marketing Mix. Estas variáveis estão apresentadas em subdivisões que são pontos de atuação da aplicação do marketing. Esta forma apresentada em ações específicas para o marketing é chamada de 4 P's, que significam Preço, Produto, Ponto de Venda (Distribuição) e Promoção. (LAS CASAS, 2005).

Tabela 1 - O Composto de Marketing com suas subdivisões

\begin{tabular}{|c|c|c|c|}
\hline $\begin{array}{l}\text { I } \\
\text { Produto }\end{array}$ & $\begin{array}{l}\text { II } \\
\text { Preço }\end{array}$ & $\begin{array}{c}\text { III } \\
\text { Ponto de } \\
\text { Venda (distribuição) }\end{array}$ & $\begin{array}{l}\text { IV } \\
\text { Promoção }\end{array}$ \\
\hline $\begin{array}{l}\text { Testes de } \\
\text { desenvolvimento do } \\
\text { produto } \\
\text { Qualidade } \\
\text { Diferenciação } \\
\text { Embalagem } \\
\text { Marca } \\
\text { Nominal } \\
\text { Marca } \\
\text { Registrada } \\
\text { Serviços } \\
\text { Assistência } \\
\text { Técnica } \\
\text { Garantias }\end{array}$ & $\begin{array}{l}\text { Política de } \\
\text { preços. } \\
\text { Métodos para } \\
\text { determinação } \\
\text { Descontos por } \\
\text { quantidades especiais } \\
\text { Condições de } \\
\text { pagamento }\end{array}$ & $\begin{array}{l}\text { Canais de } \\
\text { distribuição } \\
\text { Transportes } \\
\text { Armazenagem } \\
\text { Logística } \\
\text { Centro de } \\
\text { distribuição } \\
\text { Franchinsing. }\end{array}$ & $\begin{array}{l}\text { Propaganda } \\
\text { Publicidade } \\
\text { Promoção de } \\
\text { vendas } \\
\text { Venda pessoal } \\
\text { Relações } \\
\text { Públicas } \\
\text { Merchandisin } \\
\text { g Marca } \\
\text { Nominal } \\
\text { Marca } \\
\text { Registrada } \\
\text { Embalagem/ } \\
\text { rotulagem. }\end{array}$ \\
\hline
\end{tabular}

(LAS CASAS, 2005, p. 18).

Há uma nova visão quanto ao bem estar social, que o conceito de marketing não existe apenas na questão comercial, visando o lucro, e sim uma visão para o bem da sociedade, que preocupa tanto as organizações públicas, privadas e do terceiro setor. Essas práticas de marketing (mercadológicas) envolvem valores, comportamentos, práticas sociais; porém estas ações são das organizações como agentes em favor ao meio ambiente, serviços sociais, deficientes, combate à violência e a fome etc. (ZANONE, 2006).

Definido o conceito de marketing em relação ao social, percebe-se o quanto é relevante que seja aplicado no setor público, pois seus serviços envolvem não apenas as necessidades das pessoas, mas os direitos básicos do cidadão, como a saúde, a educação, a segurança, o transporte, entre outros. Kotler e Lee (2007) traz essa ligação do marketing na visão social implantada no setor público. Mesmo que inicialmente o marketing seja 
confundido com propaganda, e que tenha uma má compreensão sobre sua inserção nas atividades públicas, o autor compreende o papel do marketing no setor público e seu objetivo social na valorização do cidadão-usuário.

Para Kotler e Lee (2007) o marketing aplicado no setor público não somente faz a valorização do cidadão-usuário, mas também é ferramenta de estratégias que atinjam resultados que sejam compatíveis com:

- Aumento das receitas

- Aumento de utilização de serviços

- Aumento de compra de produtos

- Aumento de aceitação das leis

- Melhoria de saúde e segurança públicas

- Aumento de ações do cidadão para proteger o meio ambiente

- Diminuição de custos para entrega de serviços

- Melhoria da satisfação do cliente

- Criação de programas de apoio ao cidadão

O marketing contribui para a melhor colocação das ferramentas de aproximação do Estado à população, fazendo-se um ponto de ligação do que o serviço público pode melhorar de acordo com as exigências do cidadão-usuário, exercendo a cidadania destes, além de melhorar a imagem do Estado, trazendo mais credibilidade e confiança dos usuários. (OLIVEIRA et al, 2013).

O marketing público, segundo Oliveira, et al. (2013) é uma considerável prática na criação de um canal de comunicação voltado ao cidadão, que não apenas recebe os serviços, mas participa ativamente, favorecendo no fortalecimento do Estado em atender aos seus interesses. As ações específicas do marketing público podem atender a determinados objetivos, conforme esses autores, tais como:

- Imagem - Fortalece a imagem interna da instituição, estimula o exercício da cidadania da população e desperta seu interesse em participar das questões de interesse público.

- Pesquisa - Reduz desigualdades, promove reflexão mais ampla das políticas públicas em relação aos desejos e interesses dos usuários, assim garantindo serviços mais bem direcionados e eficazes aos interesses da coletividade.

- Comunicação - Publicar as ações da instituição, criar sistemas de comunicação, contribuindo com o desenvolvimento da gestão e promovendo sua responsabilização.

- Relacionamento - Reforça o compromisso dos servidores em atender o interesse público, fortalece a responsabilidade com o serviço prestado e criando uma relação de fidelidade com o usuário, valorizando a participação. 
Ao apresentar práticas de pesquisas de marketing para detectar as possíveis soluções ou problemas no serviço público, o estudo de Gilbert et al. (2000) descreve sobre a avaliação de usuários e sua satisfação com serviços públicos prestados. Na defesa na ideia de que os usuários dos serviços públicos são mais frágeis ao ponto de reivindicação dos direitos e de cobrar por melhoria na qualidade do serviço em comparação aos usuários do serviço privado. A fragilidade na implantação das políticas públicas baseadas em interesses políticos e sociais, ao invés de focar nos interesses dos cidadãos, fazem os gestores não observarem os problemas de insatisfação dos usuários, além de não haver forças de mercado que a façam identificar esses problemas.

O estudo de Gilbert et al. (2000) concluiu que a medida que os usuários dos serviços públicos possuem algum tipo de influência dentro da agência pública, seu nível de satisfação aumenta. E defende a avaliação por parte das agências através de seus usuários para que não tenha uma visão distorcida dentro da organização sobre o desempenho do serviço prestado, assim adotando ações que melhorem o uso de seus recursos em atendimento à população.

Vale acrescentar que os indicadores de satisfação dos usuários estão de acordo com o serviço que o órgão público presta e a liberdade de escolha do cidadão em usufruí-lo. E no campo da ação é equivalente o setor público atingir a mesma ou até superar os níveis de satisfação em comparação às empresas privadas. Já as agências que possuem usuários dependentes dos serviços públicos, não existem esta liberdade de escolha e os indicadores de desempenho não estejam devidamente apropriados para a realidade da organização. Sendo assim, é importante definir os indicadores para cada tipo de usuário, seja ele independente ou cativo desses serviços. (GILBERT et al., 2000).

Devida a esses agentes que implicam na qualidade do serviço público se faz a impotância dos estudos em marketing para o conhecimento do perfil de seus usuários, e assim garantir que os serviços públicos prestados sejam bem sucedidos em sua execução

\subsection{Comportamento do Consumidor}

Exposto sobre a importância do marketing aplicado para o bem social, um mecanismo de melhora no atendimento e/ou no produto oferecido há um estuo específico para identificar o perfil dos usuários dos serviços. Em perspectiva de mercado, percebe-se que o consumidor não é só influenciado pelas ações de marketing (relacionadas a produto, preço, distribuição/ ponto de venda e comunicação/promoção), mas também por influências sociais (as questões culturais, as classes sociais, a renda, o grupo, as pessoas de referência). Pois, as opiniões, os sentimentos e as ações dos consumidores, dos grupos de consumidores-alvo e da sociedade em geral mudam constantemente (PETER; OLSON, 2009).

Phillip Kotler define: “(...) O campo do comportamento do consumidor estuda como as pessoas, grupos e organizações selecionam compram, usam e descartam artigos, serviços, ideias ou experiências para satisfazer suas necessidades e seus desejos." (KOTLER, 2000, p.182). Ou seja, investigar os clientes para um conceito mais íntimo e pessoal, assim compreendendo empiricamente suas necessidades, supre-as dando ao produto e/ou serviço desejado. 
Consumidor é dinâmico e envolve interações e trocas, além do processo de decisão. Decisão não apenas no momento de decidir pela escolha de determinado produto ou serviço, mas no momento de definir como, quando e onde consumir e descartar. É nesse ponto que várias instituições são obrigadas a inovar constantemente para oferecer maior qualidade aos clientes para continuar mantendo sua lucratividade ou seus objetivos. (KOTLER, 2000).

Para Peter e Olson (2009), o Comportamento do Consumidor é delimitado por trocas. No entanto, é uma área de estudo complexa e foco de grande estudo acadêmico, como ênfase nas experiências, objetivos e métodos. Nessa perspectiva, esses autores defendem que o comportamento do consumidor deve ser dividido em três abordagens: Interpretativa, Tradicional e Ciência do Marketing, e na prática estas abordagens envolvem estudos acadêmicos de Antropologia, Psicologia, Sociologia e Economia.

Conforme Peter e Olson (2009), os fatores de análise que fazem o consumidor adquirir um produto/serviço são importantes para a estratégia de marketing:

1. Afeto e Cognição do Consumidor: estão relacionados aos sentimentos em relação a estímulos e eventos, e as suas opiniões, respectivamente.

2. Comportamento do Consumidor: está relacionado às ações físicas que podem ser observadas e avaliadas por outras pessoas, também chamado de comportamento observável.

3. Ambiente do Consumidor: relacionado a coisas externas que influenciam na maneira como pensa e age, o que incluem estímulos sociais, como a conduta de outras pessoas e culturas, grupos de referência.

Dessa forma, demonstra-se necessário que os profissionais de marketing tenham compreensão de como os consumidores se comportam, os papéis que desempenham, que tipo de clientes eles estão lidando, com quem esses clientes vivem, e que tipos de influências recebem para melhor propor e fazer as melhores estratégias. Além disso, esses profissionais entendam de modo explícito qual o significado do produto e as marcas para consumidores, e especialmente o que influencia o ato de fazer compras, a compra em si e o consumo (PETER; OLSON, 2009).

Segundo Kotler (2000), o comportamento do consumidor está dividido em quatro fatores que são amplamente estudados pelos profissionais em marketing para definir o perfil do consumidor e compreender os aspectos que influenciam em suas escolhas, e assim direcionar seus produtos e/ou serviços de acordo com as informações adquiridas.

Para melhor entendimento, os quatro fatores estão em duas vertendes: externas (fatores sociais e culturais) que denotam a influência do consumidor por parte de outras pessoas e internas (fatores pessoais e psicológicos), que significam as percepções do indivíduo em relação ao consumo. Estes fatores serão apresentados no tópico a seguir.

\subsection{FATORES QUE INFLUNCIAM O COMPORTAMENTO DO CONSUMIDOR}

Para Kotler (2000), pode-se observar que o consumidor é influenciado por vários fatores dentre os quais são: os fatores culturais, sociais, pessoais e psicológicos. 


\subsubsection{Fatores Culturais}

Os fatores culturais estão em três subdivisões: Cultura, Subcultura e Classe Social.

- Cultura: o principal fator que determina o comportamento e desejo de um indivíduo. Este fator é o que influencia nos valores, percepções, ações de familiares e preferências.

- Subcultura: é o que constitui a cultura, que constituídas referem-se aos grupos de identificação e socialização (nacionalidade, religião, etnia, regiões geográficas).

- Classe Social: divisão que influencia não somente pela questão de renda, mas também em fatores como empregabilidade, o nível escolar, moradia, lazer e outros que acabam se assemelhando entre pessoas da mesma classe social.

\subsubsection{Fatores Sociais}

Os fatores sociais são os que rementem aos grupos sociais nos quais as pessoas se inserem, os quais são os grupos de referência, família, papéis sociais e status.

- Grupos de referência: são grupos de pessoas que influenciam diretamente ou indiretamente as ações e comportamentos do indivíduo. Os grupos que influenciam de forma direta são denominados grupos de afinidade. Os grupos que não fazem parte diretamente ao cotidiano de uma pessoa, mas a que influencia são chamados de grupos de aspiração, já os grupos que os mesmos possuem rejeição são chamados grupos de dissociação.

- Família: grupo mais importante na organização, sendo o mais influente. Há duas subdivisões que fazem a influência familiar ser mais ou menos enfático, sendo a família de orientação sendo direcionada aos pais e irmãos, e a família de procriação.

- Papéis sociais e status: uma posição no qual a pessoa está inserida ou conjunto de atividades que esta pessoa pratica podem ser fatores que contribuem para o comportamento do consumidor. O papel refere-se a estas atividades que a pessoa desempenha, e o status é o nível de "importância e responsabilidade" que fazem na sociedade.

\subsubsection{Fatores Pessoais}

Fatores pessoais como idade, ocupação, personalidade, estilo de vida e autoimagem são influências consideradas importantes para determinar o comportamento do consumidor.

- Idade e estágio de vida: à medida que um indivíduo cresce, ele muda as necessidades, gostos e afinidades. Assim a idade e o estágio de vida são fatores consideráveis, como exemplo o modo de consumo de um bebê é diferente de uma pessoa adulta. Uma pessoa casada com filhos difere de quem está solteira e assim por diante.

- Ocupação e circunstâncias econômicas: a escolha de um produto ou serviço também interfere na questão da situação econômica no qual a pessoa se encontra, como a renda, patrimônio, o quanto pode gastar ou economizar. 
- Estilo de Vida: padrões de vida que o indivíduo está de modo geral, representando a pessoa de uma forma mais completa, interligando outros fatores como atividades, interesses e opiniões.

- Personalidade e autoimagem: a autoconfiança, domínio, autonomia, e outros aspectos referentes à personalidade influem para o comportamento de consumo. Além da questão da autoimagem, como a pessoa vê a si mesmo, como ela gostaria de ser e o que os outros a veem também são formas de estudo na escolha de consumo.

\subsubsection{Fatores Psicológicos}

Há quatro fatores psicológicos que determinam a escolha de compra ao comportamento do consumidor.

- Motivação: o que faz a pessoa ter a necessidade de ter uma ação, esta necessidade faz com que a pessoa internamente busque aquilo que almeja, seja para suprir necessidades básicas de sobrevivência ou as questões sociais ou de estima.

- Percepção: é a situação em que o indivíduo analisa, seleciona e interpreta as informações adquiridas externamente. Existem três processos de percepção: atenção seletiva, distorção seletiva e retenção seletiva.

- Aprendizagem: a experiência é o que faz a mudança no comportamento de uma pessoa. Maior parte do que se pratica no comportamento do ser humano é aprendida.

- Crenças e Atitudes: crença é o pensamento que uma pessoa tem sobre uma determinada coisa, situação. Tem como base o conhecimento, opinião ou fé. Já a atitude refere-se aos sentimentos, avaliações e influências de ações a uma coisa ou situação.

Seguindo o pensamento de Kotler (2000), Las Casas (2005) adquire os fatores do comportamento do consumidor separados por duas formas de influência, os internos e externos. Os fatores internos estão relacionados à motivação, aprendizagem, percepção e personalidade do indivíduo. Os fatores externos se referem à família, classe social, grupos de referência e cultura.

Além dos fatores que contribuem para influenciar o processo de objetivo do consumidor, há os procedimentos que fazem o usuário adquirir o produto e/ou serviço. As etapas que seguem o interesse do usuário até o sentimento de pós compra, o que causa o sentimento de satisfação ou ansiedade do consumidor, assim descritas por Las Casas (2005) são:

- Necessidade: importância ou relevância em consumir determinado produto ou serviço.

- Informações: busca por informações a respeito do produto, como durabilidade, qualidade, atendimento, facilidade.

- Avaliação: busca por informações sore a oferta, preço, benefícios e diferenciais apresentados a cada um.

- Decisão: escolha definida do produto mais vantajoso e a compra efetuada.

- Pós-Compra: desiquilíbrio psicológico sobre a escolha do produto e/ou serviço já que existe um sentimento de dúvida ao aderi-lo. 
O comportamento do consumidor é um segmento importante no estudo do marketing para avaliação a fim de satisfazer o cliente. Já que o cidadão é cada vez mais consciente de seus direitos, conhecer o perfil do usuário do produto/serviço se torna um diferencial para o alcance de serviços públicos eficientes, eficazes e efetivos.

\section{METODOLOGIA}

A pesquisa caracteriza como tipo descritiva, ao ser definido como fatos observados sem a interferência do pesquisador, sendo seus dados obtidos por meio de coleta de dados. Em relação ao delineamento, classifica-se como pesquisa quantitativa, o que envolve um estudo de pesquisa aplicado, requerendo uso de recursos estatísticos para a elaboração dos resultados. Quanto ao método, a pesquisa trata de um estudo de caso, que abrange o conjunto de atividades para um determinado grupo social, respeitando sua totalidade. (ANDRADE 2005).

A técnica estatística para a realização desta pesquisa foi a Análise Fatorial Exploratória, que busca avaliar através de um conjunto de variáveis, identificar as dimensões de variabilidade comuns existentes em um conjunto de fenômenos, sendo o objetivo de desvendar estruturas existentes, mas não observáveis diretamente, ou seja, a análise fatorial ou $\mathrm{AF}$, tentar descrever um conjunto de variáveis através de um número menor de dimensões chamados fatores (CORRAR; PAULO; DIAS FILHO, 2007).

O IFRN de Ceará-Mirim encontra-se no ano de 2015 em funcionamento com 240 (duzentos e quarenta) alunos matriculados nos cursos técnicos integrados. Foram considerados 205 questionários válidos para a análise, sendo 133 do curso Técnico em Informática $\left(1^{\circ}\right.$ e $2^{\circ}$ anos), e 72 do curso de Técnico em Programação em Jogos Digitais $\left(1^{\circ}\right.$ ano).

O questionário foi dividido em duas seções. A primeira seção contendo as questões relacionadas aos fatores sociais, pessoais e psicológicos, que refletia sobre as influências que os alunos tinham e suas motivações (neste caso, o fator cultural não foi considerado por apresentar maior complexidade de estudo, referindo-se além do ambiente da instituição). Nessa seção, foram utilizadas questões sobre a influência e a motivação investigadas no estudo de caso de Martins (2006); e questões sobre estilo de vida, investigadas na dissertação de mestrado em Administração de Machado (2009). E na segunda seção do questionário, o foco foi sobre o perfil dos alunos em relação a gênero, estilo de vida, faixa etária, renda, ocupação e curso na instituição.

\section{RESULTADOS E DISCUSSÕES}

\subsection{O perfil dos alunos do IFRN - Campus Ceará-Mirim}

O perfil dos alunos foi analisado nos seguintes aspectos: gênero, renda, faixa etária número de pessoas por casa, estado civil e emprego com carteira assinada. Em relação ao gênero dos alunos, identificou-se que 56,37\% são do sexo masculino e 45,63 são do sexo feminino, apesar da pequena diferença, não há um ponto considerável nesse aspecto. 
Na questão ao estado civil dos alunos, os resultados apresentaram que estes em sua predominância são solteiros, com 97\%. Com relação à faixa etária, 38,69\% dos alunos encontram-se com 15 anos, $12 \%$ a mais que os alunos de 16 anos. Apenas 6,03\% dos alunos estão com 18 anos. No aspecto do trabalho com carteira assinada, mostrou-se que os alunos da instituição apenas estudam, afirmando $95,59 \%$ dos respondentes. seguir:

Em relação à renda familiar, o resultado será apresentado de acordo com o gráfico a

Gráfico 1- Renda Familiar dos Alunos no IFRN (em \%)

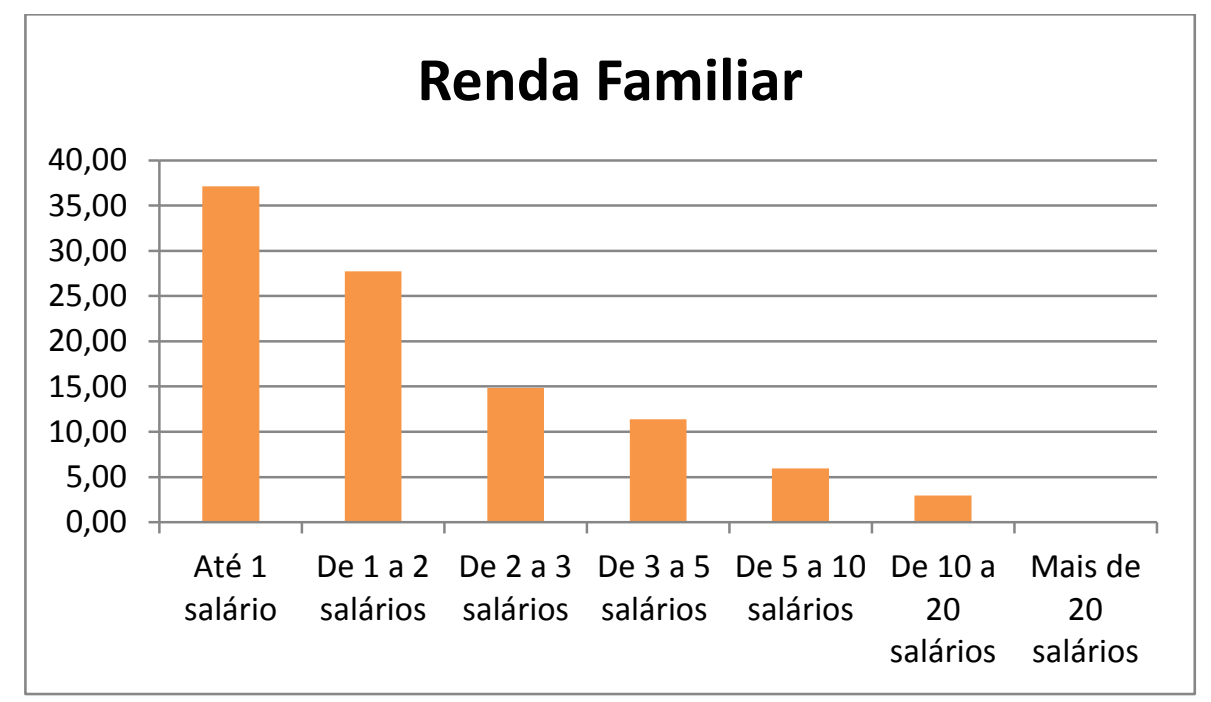

O gráfico 2 representa que os alunos que possuem até um salário mínimo mostrou ser a maioria com 37,13\%, seguido de um a dois salários mínimos, com 27,72\%. Os alunos que apresentavam renda familiar entre dez e vinte salários mínimos ficaram em apenas $2,97 \%$.

Com relação à conclusão do ensino fundamental dos alunos do IFRN - Campus Ceará-Mirim, será apresentado de acordo com o gráfico a seguir:

Gráfico 2 - Conclusão do Ensino Fundamental dos Alunos do IFRN (em \%)

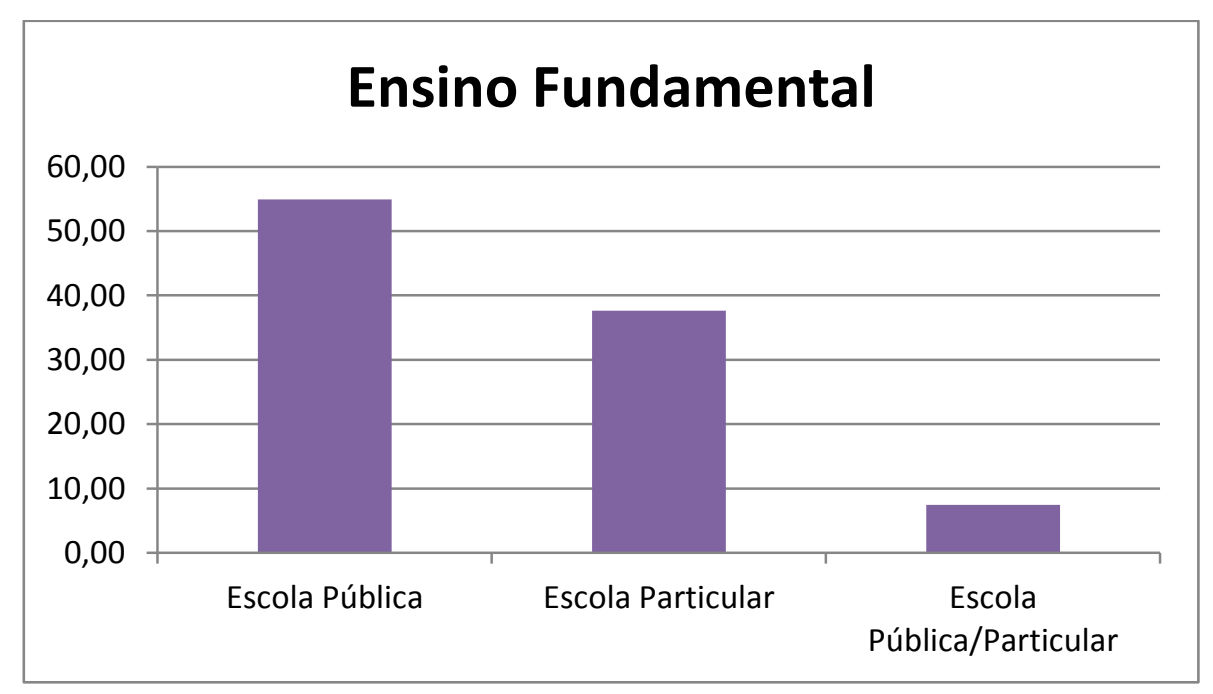


Ao observar a relação dos estudantes à conclusão do ensino fundamental, 54,95\% dos alunos concluiu somente em escola pública, sendo perceptível o intuito inicial do ingresso dos alunos estar de acordo com a função social da instituição. Apesar do considerável número de $37,92 \%$ dos alunos vindos de escolas particulares, $7,43 \%$ dos alunos concluíram em escolar públicas e particulares.

Ao se tratar da quantidade de moradores por casa, mostra-se que em sua maioria, os alunos vivem com até quatro (4) pessoas, com $31,22 \%$ dos respondentes, e estudantes que vivem com até cinco (5) pessoas em casa está em 27,80\%.

Portanto, conclui-se que o perfil dos alunos do IFRN - Campus Ceará-Mirim, são estudantes concluintes do ensino médio em escolas públicas, com renda entre um a dois salários mínimos, solteiros e com a maioria reside com quatro pessoas. Essas informações demonstram que o IFRN vem satisfazendo a sua função social de atender os esses alunos, e transformar a realidade na perspectiva da igualdade e da justiça social.

\subsection{Análise Fatorial Exploratória - Os fatores que influenciam o ingresso dos alunos do IFRN}

O critério utilizado para verificar a quantidade de variância total dos dados é o Kaiser test, que pode estar relacionado a um fator específico. Para a execução dessa análise, foi utilizada a rotação ortogonal Varimax, por facilitar a identificação das variáveis relacionadas aos fatores, o que projeta cargas fatoriais em um fator único.

O início dessa análise foi executado com um processo de eliminação das variáveis que não apresentavam autoimagem maior ou igual a 0,5 e comunalidades abaixo de 0,6 índices descritos na literatura de Corrar, Paulo e Dias Filho (2007). A criação dessas variáveis foi através dos estudos de Martins (2006) e de Machado et. al. (2009), que são afirmações relativas aos fatores sociais, psicológicos e pessoais, aplicadas nos estudos de Silva e Tacconi Neto (2013) e Nascimento e Tacconi Neto (2015). Foram criadas cinquenta e nove (59) variáveis, sendo estas cinco (5) relacionadas a fatores sociais, trinta (30) relacionadas aos fatores pessoais e vinte e quatro (24) relacionadas aos fatores psicológicos.

Com a rotação de 59 variáveis, foram necessárias dez (10) rotações ortogonais da análise fatorial, chegando a vinte e duas (22) variáveis. O desenvolvimento dessas análises chegou a sete fatores que serão apresentados através do teste de KMO, Teste de Bartlett, Comunalidades e percentual da variância explicada por fator.

O teste de KMO é o indicador do grau de explicação a partir dos fatores encontrados na análise fatorial. Para que este indicador esteja em grau satisfatório, precisa-se estar acima de 0,5 (CORRAR; PAULO; DIAS FILHO, 2007). Nesta pesquisa a análise indicou o grau 0,838 , sendo considerado satisfatório ao descrever as variações dos dados originais. $\mathrm{O}$ teste de Bartlett analisa a esfericidade e valida a utilização da Análise Fatorial, assim apresentado na Tabela 2.

Tabela 2 - KMO e Teste de Bartlett da variável desempenho operacional

\begin{tabular}{l|c}
\hline Medida de adequação da amostra: Kaiser-Meyer-Olkin & 0,838 \\
\hline Teste de esfericidade de Bartlett's & $2.143,069$ \\
\hline P-valor & 0,000 \\
\hline
\end{tabular}


O próximo ponto sobre a o cálculo estatístico refere-se às Comunalidades, que avaliam o poder de explicação dos fatores. Na análise apresentada as comunalidades apresentaram os níveis de extração acima de 0,6, de acordo com a Tabela 3.

Tabela 3 - Comunalidades

\begin{tabular}{c|c}
\hline \multicolumn{2}{c}{ Comunalidades } \\
\hline Variável & Extração \\
\hline VAR00011 & 0,847 \\
\hline VAR00013 & 0,848 \\
\hline VAR00014 & 0,801 \\
\hline VAR00022 & 0,616 \\
\hline VAR00033 & 0,683 \\
\hline VAR00034 & 0,628 \\
\hline VAR00037 & 0,747 \\
\hline VAR00038 & 0,832 \\
\hline VAR00039 & 0,715 \\
\hline VAR00042 & 0,794 \\
\hline VAR00043 & 0,719 \\
\hline VAR00045 & 0,671 \\
\hline VAR00046 & 0,651 \\
\hline VAR00049 & 0,709 \\
\hline VAR00050 & 0,809 \\
\hline VAR00051 & 0,668 \\
\hline VAR00052 & 0,688 \\
\hline VAR00053 & 0,757 \\
\hline VAR00054 & 0,654 \\
\hline VAR00055 & 0,708 \\
\hline VAR00056 & 0,686 \\
\hline VAR00057 & 0,723 \\
\hline
\end{tabular}

A Matriz Rotacionada distribui a porcentagem de variância explicada em cada variável, assim gerando os fatores relacionados. Ao presente estudo apresenta a porcentagem de variância que gerou os sete fatores que serão apresentados na tabela 4 . 
Tabela 4 - Matriz Rotacionada das variáveis significativas do estudo.

\section{FATORES}

\begin{tabular}{|c|c|c|c|c|c|c|c|}
\hline & 1 & 2 & 3 & 4 & 5 & 6 & 7 \\
\hline VAR00049 & 0,756 & & & & & & \\
\hline VAR00050 & 0,844 & & & & & & \\
\hline VAR00051 & 0,783 & & & & & & \\
\hline VAR00052 & 0,782 & & & & & & \\
\hline VAR00053 & 0,844 & & & & & & \\
\hline VAR00037 & & 844 & & & & & \\
\hline VAR00038 & & ,862 & & & & & \\
\hline VAR00039 & & ,757 & & & & & \\
\hline VAR00046 & & & 0,456 & & & & \\
\hline VAR00054 & & & 0,697 & & & & \\
\hline VAR00055 & & & 0,762 & & & & \\
\hline VAR00056 & & & 0,599 & & & & \\
\hline VAR00057 & & & 0,747 & & & & \\
\hline VAR00042 & & & & 0,855 & & & \\
\hline VAR00043 & & & & 0,793 & & & \\
\hline VAR00045 & & & & 0,575 & & & \\
\hline VAR00022 & & & & & 0,658 & & \\
\hline VAR00033 & & & & & 0,754 & & \\
\hline VAR00034 & & & & & 0,744 & & \\
\hline VAR00011 & & & & & & 0,898 & \\
\hline VAR00013 & & & & & & $-0,905$ & \\
\hline VAR00014 & & & & & & & 0,884 \\
\hline
\end{tabular}

Diante da tabela 4, os fatores que influenciam na escolha por estudar um curso superior no IFRN Campus Ceará-Mirim podem ser divididos em sete fatores. Esses fatores foram nomeados de acordo com as características do grupo de variáveis envolvidas e dispostas por relevância conforme apresentado a seguir: 
- Fator 1 - Infraestrutura

- Fator 2 - A Marca da Instituição

- Fator 3 - Mercado de Trabalho

- Fator 4 - Percepção sobre o Prestígio da Instituição

- Fator 5 - Ascensão Pessoal

- Fator 6 - Relação ao Esporte

- Fator 7 - Família

O primeiro fator é referente a infraestrutura do IFRN - Ceará-Mirim. Segundo os alunos, IFRN tem salas amplas, confortáveis e climatizadas, além de possuir equipamentos como projetores, TV, vídeo entre outros. Também foram citados os laboratórios de informática bem equipados e a disponibilidade de acesso gratuito à internet. Ou seja, o primeiro fator que influenciou os alunos do IFRN ao ingresso foi composto por variáveis psicológicas. Esse aspecto demonstra que os investimentos públicos realizados nessas novas unidades e o impacto que essas construções promovem na valorização e na estética da cidade, tendem a transformar essas instituições em objeto de desejo para o consumo de serviços educacionais.

O segundo fator considerado pelos alunos, a marca, é formado pelo fato da instituição oferecer diploma reconhecido no mercado de trabalho, e por ser uma marca forte, sólida e admirada entre as demais instituições de ensino no mercado. Este fator foi composto por variáveis psicológicas, que denotam a percepção dos alunos sobre a relevância do IFRN no mercado, que é importante para o reconhecimento profissional, o que se denota a expectativa dos alunos em serem reconhecidos por estudarem em uma instituição com credibilidade de mercado, que compete-se com instituições privadas.

Em relação ao terceiro fator, os alunos acreditam que o IFRN é uma instituição que vai ajudá-los a conseguir um bom emprego; oferecendo uma excelente estrutura curricular e possuindo professores atualizados, com experiência no mercado, além de facilitar o encaminhamento de seus alunos para os estágios em empresas. O terceiro fator também foi composto por variáveis psicológicas, ao observar que a instituição ofereça um diploma reconhecido, o que seria consequência da credibilidade na qualidade de ensino. Os alunos do IFRN obtêm boa aceitação no mercado de trabalho, sendo que teriam mais aceitabilidade em sua atuação profissional.

O quarto fator é referente aos alunos considerarem que a instituição dá prestígio aos seus alunos, sendo um símbolo de status em seu meio social, o fato das empresas preferem contratar profissionais que se formam na instituição, e que pessoas bem sucedidas ou vencedoras estudaram no IFRN. A instituição traz uma crença de que, alguém que tenha estudado no IFRN tem boa recepção no mercado de trabalho, onde os alunos concluintes têm maiores chances de conseguir uma carreira profissional bem sucedida. Essa informação é percebida pelos alunos por uma imagem externa que a instituição possui junto à sociedade. Como estas impressões vem da percepção dos alunos, são consideradas a um fator psicológico.

O quinto fator está relacionado às expectativas de crescimento pessoal, composto por variáveis voltadas aos fatores pessoais, o que difere dos fatores anteriores. As afirmações dos alunos mencionam, tem relação em pensar nas coisas que pretendem 
conquistar e trabalhar para consegui-las. Os alunos consideram-se com boa bagagem cultural e acreditam que suas vidas estarão melhores daqui a cinco anos. Assim, na perspectiva da auto-imagem dos alunos, o IFRN é um meio para a realização de suas metas de crescimento não só no campo profissional, mas também pessoal. Esse fator mostra que existe um sentimento de realização ao estudar no IFRN, já que esta será uma porta de entrada para oportunidades de se tornarem pessoas melhores com relação ao ser bem sucedido na vida.

O sexto fator demonstra as afirmações mais relevantes dos alunos o gosto por esportes em equipe e não gostar de esportes, duas variáveis pessoais desse fator. A relevância pode justificar que no município de Ceará-Mirim tenha uma forte tradição dos esportes em equipe como futebol, handebol e vôlei, que são altamente incentivados nas escolas do município. Porém, é de considerar que nem todos os alunos gostam ou possuem habilidades para a prática de esportes, o que é compreensível a evidência da afirmação por não gostar de sua prática. Vendo a realidade que em outras instituições, pode ser que a tradição esportiva exista, mas não bem aceita por todos os alunos da instituição. O quinto fator é formado por variáveis relacionadas aos fatores pessoais, que neste caso, estaria ligado ao estilo de vida dos alunos.

A afirmação que se criou o sétimo fator pessoal é a importância da família aos alunos. $\mathrm{O}$ que pode justificar o ingresso no IFRN à influência familiar ou uma conquista para ser mais bem aceito em seu meio, tendo como evidência o quarto fator (Percepção sobre o Prestígio da Instituição). A família é o principal meio social das pessoas e tem o maior impacto tanto de receber influências, quanto em influenciar. Ser ou ter algo relativamente importante é consequência da necessidade de ser bem acolhido no meio familiar, é um ponto importante para a personalidade e o estágio de vida em que o aluno se encontra.

Portanto, os resultados da análise fatorial desenvolvida evidenciam que os fatores que mais influenciaram na escolha dos alunos do IFRN Campus Ceará-Mirim foram infraestrutura, a marca da instituição, mercado de trabalho e percepção sobre o prestígio da instituição, ambas relacionadas às variáveis psicológicas. Os fatores de ascensão pessoal, relação ao esporte e família evidenciaram variáveis pessoais. Nenhum fator social foi considerado pertinente estatisticamente na influência dos alunos em ingressarem no IFRN.

\section{CONCLUSÕES}

Conforme o objetivo geral deste estudo, conclui-se que os fatores psicológicos e pessoais foram os mais evidentes na escolha dos alunos ao IFRN Ceará-Mirim, e os fatores sociais não foram considerados para a escolha da instituição. O perfil dos alunos foi identificado como estudantes oriundos de escolas públicas, com renda familiar de um a dois salários mínimos mensais. A faixa etária está por volta dos quinze anos de idade. Esse perfil demonstra que o IFRN de Ceará-Mirim atende a sua função social de oferecer educação profissional e tecnológica para transformar a realidade em relação a igualdade e justiça social.

Dessa forma, o IFRN deve ter como ações em relação aos desejos e expectativas dos alunos, continuar investindo na qualidade dos ambientes de estudo e na estrutura física, elevando a qualidade. Divulgar as ações e projetos bem sucedidos do IFRN, para fortalecer 
a marca e trazer incentivos para o mercado de trabalho, como o empreendedorismo, e garantir a oferta de cursos para o mercado local. Além de criar ações de incentivo ao aluno para as habilidades individuais, enriquecendo o conhecimento e contribuindo junto com a sociedade, levando o nome da instituição através de seus alunos e mantendo o prestígio em que a instituição se encontra no mercado.

Os estudos de marketing e comportamento do consumidor, aliados a metodologia de análise fatorial exploratória, foram a ferramenta necessária de se quantificar os pontos qualitativos a visão dos alunos sobre a instituição neste estudo. Assim apresenta uma forma de descobrir em pesquisas comumente aliadas ao setor privado - tendo em vista o cliente, direcionada para o setor público, sendo o público-alvo o cidadão-usuário, que contribui com seus impostos e exige retorno transformado em serviços de qualidade para a sociedade.

Ao tratar-se de novas pesquisas, sugere-se estudo de identificação das influências dos alunos do IFRN de outros Campi, tanto para os ingressantes quanto para os que estão no último ano de curso. Nessa perspectiva, comparam-se as influências Também se sugere estudos sobre a relação dos alunos com o curso estudado, se tratando da empregabilidade após conclusão e da disponibilidade de mercado local.

\section{REFERÊNCIAS}

1. ANDRADE, Maria Margarida de. Introdução à metodologia e ao trabalho científico: elaboração de trabalhos na graduação. 7. ed. São Paulo. Atlas, 2005.

2. CORRAR, Luiz J.; PAULO, Edilson; DIAS FILHO, José Maria (Coord.). Análise multivariada: para cursos de administração, ciências contábeis e economia. São Paulo: Atlas, 2007.

3. GILBERT, G. Ronald; NICHOLLS, J.A.F; ROSLOW, Sydney. A mensuração da satisfação dos clientes do setor público. Revista do Serviço Público. Ano 51. N 3. p. 28-39. Jul/Set 2000.

4. IFRN - Instituto Federal de Educação Ciência e Tecnologia do Rio Grande do Norte. Institucional. Disponível em: http://portal.ifrn.edu.br/institucional . Acesso: 16 jul. 2015.

5. KOTLER, Philip; LEE, N. Marketing no setor público: um guia para um desempenho mais eficaz. Porto Alegre: Bookman, 2007.

6. KOTLER, Phillip. Administração de marketing: a edição do novo milênio. Análise de mercados consumidores e do comportamento de compra. Tradução Bazán Tecnologia e Linguística. São Paulo. Prentice Hall, 2000.

7. LAS CASAS, Alexandre Luzzi. Marketing: conceitos, exercícios, casos. 7a Ed. São Paulo: Atlas, 2005.

8. MACHADO Carlos Henrique. Autoconceito, estilo de vida e consumo de vestuário de moda feminina. 2009. 122 f. Dissertação (Mestrado em Administração) - Centro de Pesquisa e Pós-Graduação em Administração da Universidade Federal do Paraná. 
9. MARTINS, Jane Maria Diniz. Marketing educacional: um estudo sobre atributos e imagens das instituições de ensino superior. 2006. $157 \mathrm{f}$. Dissertação (Mestrado em Administração) - Fumec - Fundação Mineira de Educação e Cultura.

10. NASCIMENTO, Elilde Varela do. TACCONI NETO, Ernesto Alexandre. Análise dos fatores que influenciam o cidadão-usuário dos serviços do IFRN Campus Natal Central. ENEGEP - Encontro Nacional de Engenharia de Produção. Fortaleza, 2015.

11. OLIVEIRA, Aline Lourenço de, et al. O marketing público no contexto da reforma gerencialista do estado. Revista de Gestão do Unilasalle. Canoas, v. 2, n. 2, $2013 . \quad$ set. Disponível em http://www.revistas.unilasalle.edu.br/index.php/desenvolve . Acesso em 07 agosto de 2014.

12. PETER, Paul J.; OLSON, Jerry C. Comportamento do consumidor e estratégia de marketing. Tradução: Beth Honorato. 8. ed. - São Paulo: McGraw-Hill, 2009.

13. SILVA, Alex Marchezan Paiva da; TACCONI NETO, Ernesto Alexandre. Análise dos fatores que influenciam o cidadão-usuário dos serviços do IFRN campus Natal Zona Norte. Extremoz: UFRN/ Biblioteca, 2013.

14. ZANONE, Luiz Cláudio. Marketing social. São Paulo: Thomson Learning, 2006. 